\title{
Education for Sustainable Development (ESD) in Indonesia: A Conceptual Framework
}

\author{
Satrianawati ${ }^{a, 1, *}$, Wen Heng Fu ${ }^{\text {a,2 }}$ \\ ${ }^{a}$ Universitas Ahmad Dahlan, Harbin Normal University China \\ ${ }^{\mathrm{b}}$ Harbin Normal University, China \\ ${ }^{1}$ satrianawati@pgsd.uad.ac.id*; ${ }^{2}$ wenhengfu@126.com \\ * corresponding author
}

ARTICLE INFO

Article history

Received 2019-06-06

Revised 2019-06-010

Accepted 2019-06-17

Keywords

Online school

School as a disaster

Education for sustainable development

\section{ABSTRACT}

Some schools in some areas of Indonesia are currently really dangerous because they are in the ring area of the fire. In the region, there are also schools located in disaster-prone areas. This research aims to describe modern education for sustainable development by building the online school as disaster solution in the modern era. This research is descriptive qualitative research using a social history approach. The design research method was carried out in four phases: data collection, data display, conclusions, and data condensation. The result of this research is that the government should be building an online school as a disaster solution for the generation in the modern era to education for sustainable development.

This is an open access article under the CC-BY-SA license.

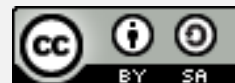

\section{Introduction}

The school in Indonesia today is perilous because the location of Indonesia is in the area ring of fire. The Ring of Fire has produced the world's most destructive and active volcanoes, not to mention most of the world's earthquakes. Read on to find out just what the Ring of Fire is and the volcanoes it has created throughout the planet's history [1]. The Ring of Fire refers to a geographical area of high volcanic and seismic activity around the edges of the Pacific Ocean. Recently, some cases have happened in Indonesia, such as tsunami, earthquake, and landslide happened in Palu, the landslide in the Lebak Banten, and the flood in Gowa, [2]. The effects of it are feeling by the citizenship of some people in some areas that happened disaster in Indonesia. Indeed, all people could not make a prediction, but society needs to understand the location of Indonesia. The geologists, the volcanologists, and the seismologists explained that the location of Indonesia is the Ring of Fire that has a vast geographic area rich in tectonic activity [3]. Thus Indonesia could not achieve a good result for all activities because the environment does not support it. Especially in the education aspect.

Impossible to success in education with bad condition. This condition driving force the government, and all stakeholder must re-thinking to all the policies that they have made. Actually, in education for sustainable development is not providing human development in their comfortable life. In other hands, anxiety becomes the first issues. The millennial generation feels frightened because of the situation. The sustainable development program needs to consider the safety condition to achieve a better education to the millennial generation for success in the Millennium era. It is not enough the Education for Sustainable (ESD) only encourages changes in knowledge, skills, values, and attitudes of millennial generation without more attention in their feeling.

Showing what the government has been doing in education until now is still some of the millennial generations not satisfied. Even though the government had changed the system, from centralization to 
decentralization. Also, the safety of the millennial generation when they are studying in school shows that some of the school are not safe because the condition of the environment, the building of the school is broken. So, the safety of children does not full attention. This is supported in some facts in some areas in Indonesia. In some cases, the infrastructure could not take a long time; the disaster come in and destroy all of the facilities of education.

Based on the condition, the strategy of ESD in Indonesia must be changed by the government in its policy. So online school is one of the solutions to decrease danger situation and decrease the anxiety in the millennial generation. Therefore for the solution of the problem education in Indonesia, in this paper will explain that limit exists only in mind of building the online school as a disaster solution for Education within Sustainable Development (ESD).

\section{Method}

This research used qualitative research [4]. Collecting data has used secondary data. Firstly, collecting data from YouTube, local news, national news, and international news, and some books. Second, data display: the data has displayed to see the relationship between education for sustainable development and disaster solution. Third, conclusions: the conclusion has used in drawing and verifying. Fourth, data condensation: to get condensation of online school is a disaster solution for education within sustainable development.

\section{Results and Discussion}

Education for Sustainable (ESD) is defined as education that encourages changes in knowledge, skills, values, and attitudes to enable a more sustainable and equitable society. ESD aims to empower and equip current and future generations to meet their needs using a balanced and integrated approach to the economic, social and environmental dimensions of sustainable development. Instead, to be sure that to continue the development program of ESD needs safety and security in their country. Moreover, an online school is one of the solutions.

Today, many people, no doubt, began hearing about internet safety since they were child enough to begin spending time online. The government should take benefit of the habitual of the millennial generation. In other hands, connecting with the internet is the lifestyle of the millennial generation. Therefore, an online school will be useful for them to use the internet appropriately. Instead, attending online school will change the millennial generation activities from seeing to innovating. The school is a place where people could get away from the world of business and commerce and, through concentration upon salvation, ensure the safety of their soul - and, through prayer rather than social interaction, help too with the salvation of others. The schools and universities have sometimes been likened to monasteries, places, like our major and prestigious private schools and like the old 'new' universities, set apart in a rural idyll, undistracted by the affairs of commerce and industry [5]. Education and school are like a shadow that could not be separated.

\subsection{An Online School: Education for Sustainable Development as A Disaster Solution}

Online school coherent with the real problem that teacher every day faced in their class is the millennial generation always see their hand-phone, for example, I-phone, Apple, Samsung, and all other android phones. If we see the habitual of the generation before the android came in 2010 and after 2010 is very different. Focused on teaching and learning activities before 2000, when Z generation is studying in elementary school. What their teacher said become their trust and they do not want to hear someone else including their parents, even though their parents have educated more than their teacher, for example, the teacher was graduate in bachelor degree and their parents was graduated in post-doctoral. Their children put their trust to the teacher not to the parents because the teacher has a special place in their mind. Different from the alpha generation in 2000. The problem in alpha generation in 2000 is shopping, and traveling becomes more attractive than studying. Therefore some teachers implementing some role models in their lesson activity. In 2010 when gadget and android phone become familiar in the home, the role of teacher step by step has been changed by Android. The millennial generation could not be separated from their phone. This role models both the teachers and the parents have already changed by the phone. To clear the description can be seen in figure 1 


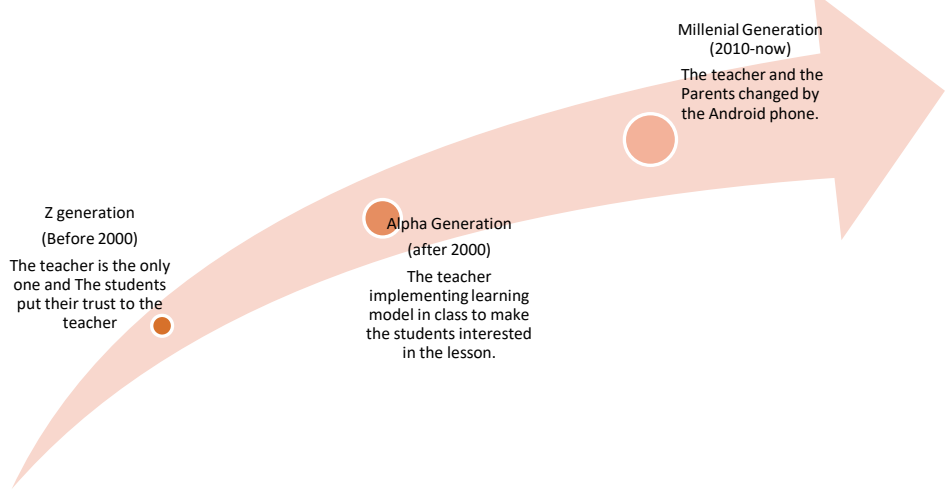

Figure 1. The position of The Teacher in a different generation

The real context happened that the reason for building an online school is not only the location of Indonesia but also the habitual of the millennial generation in which influencing the online school program. The teachers and the parents must be realizing this condition. They can make excellent cooperation to take the benefit of Android to their children and making the millennial generation use their phone in studying. Thus, an online school following their habitual action and also become an essential solution for the disaster for education within sustainable development.

Online school is the school program that the millennial generation was attending the online class. Online school becomes a disaster solution because it is easy and can be done whenever and wherever the millennial generation wants to study. Unlike regular classes, the millennial generation does not need to attend class regularly clock set by the school. In the implementation of the online school, the millennial generation attends online classes with no regular schedule, but they can attend class whenever they want with specific targets such as the amount of time required to attend online classes. In the other hand, [6] established that the Internet had made a fundamental change in this antiquated mode of communication; it has facilitated the linkages between schools and homes by enabling teachers and parents to play a more significant role in the students' learning experiences. The bond between schools and home can be strengthened through increased interaction and communication, as is evidenced in the following instances. Therefore, online school is essential for sustainable development. In online school also all topic and knowledge the students will learn.

Some researchers have been doing research and development in online book, online teaching an online task. For example [7] established that digital Learning Assets (DLAs) are interactive learning objects and are any form of content and media that have been formatted into a binary source, which includes the right to use it to facilitate learning. A digital file without the right to use it is not an asset. Digital learning assets are commonly categorized into three major groups: textual content (digital assets), images (media assets), and multimedia (media assets). DLAs are commonly found in online learning (academic course work, corporate training, etc). Various researchers supported the online school to be legal, and of course, the safety of the millennial generation is a top priority. To emphasize all statements, learning in an online school is the most excellent opportunity for the learner to have better learning.

\subsection{The curriculum in Online School: Education for Sustainable Development as A Disaster Solution}

The culture and consumption psychology has been a fundamental point curriculum in an online school. The culture of the curriculum in online school and regular school is the same. The difference comes from the process of teaching and learning. Like in regular school, the curriculum in online school also doing improvisation such as giving a lesson about the strategy to face the disaster, the method to the millennial generation for facing disaster by online and the millennial generation following it in simulation and become consumption psychology.

Even though it is different with the curriculum in the physical education but in an online school life education are consistent internally from all the aspects including essence, function, target, a role even though less of physic contacts. The curriculum in an online school is balancing the millennial generation as a modern society. It inevitably becomes modern consumers considering modern era without culture. [8] Said that modern consumers tend to push away anything commonly seen. It means the culture that developing in society, including becoming an important issue to develop curriculum. 
The curriculum in the education system has to follow the development of the country, instead of in the online school program. During this time, the low educational impact from some factors, and the teacher and the curriculum are the most important to solve the problem in education. The curriculum makes the teacher to do something, or the teacher makes their curriculum. Also, the curriculum in online school properly must arrange before doing teaching and learning. The teacher gives the lesson to the millennial generation should prepare firstly based on the curriculum. The curriculum in online school must be socialization to the millennial generation. This is a primary method to do in an online school.

The millennial generation will be active to find all material about their lesson. In another hand, if the task about around this life, it is related to the goals of the online school that the student will do it in nature without destroying their environment. Keep the environment in online school becomes a disaster solution. This is very important that the curriculum in online school teach the millennial generation to balance their habit with the environment. Also, the curriculum in an online school can anticipate what they want to study and what they forget. Moreover, if the disaster comes and destroy everything, the school always be safe, and it will be opened again without changing the curriculum system.

The curriculum in online school arranges concept teaching and learning, including the material of the disaster mitigation. By the curriculum, the teacher will make their study plan and giving it to the millennial generation in online. So the millennial generation understand what should be they do to fulfill their duties, and the teacher also understands what the millennial generation have done and what they have not been done. Also, the curriculum in online school keeps closing the millennial generation with their relatives because they can attend the class with them, such as father, mother, sister, brother, etc. Thus what the millennial generation learn also will be known by their relatives in the online curriculum system. Otherwise, an online school curriculum is always updated because the students will develop their task based on situation or condition where they live in. It means there is a hidden curriculum that always changes depending on the situation. Explained that the character education development through the hidden curriculum at disaster-prone schools possesses its uniqueness with a challenging complexity level [9]. Amazing character education values should clash with appalling natural phenomenon. Amazing character and something uniqueness in education have a big challenge for students to develop their ability. To be sure, the curriculum in online school give a new color in education.

The curriculum in online school makes a challenge between the teachers and the students to do a new program in major. The teacher has to make a creation in the program. For example, [10] established a 2-year study involving primary children learning mathematics through the use of mobile devices and apps. With the teachers as co-researchers, they examined teacher practice and the interconnectivity between teacher pedagogy and the affordances of the apps. In online curriculum school using mobile devices and apps is the way to attend class. Also, the teachers used a diverse range of apps, including ones for screen-casting and coding, with the various learning experiences and opportunities for influencing the learning outlined and considered. For interesting the students to study the teacher have to make an exciting theme. Therefore, the curriculum in online school has implemented in various aspects, and developing a global perspective across the curriculum involves exploring the rich diversity of social worlds across cultures. The students get a challenge for a global educational competition and give a contribution to sustainable development in the world based on where they live.

\subsection{The concept of teaching and learning in online school}

Teaching and learning in an online school is a new program expected to meet the necessity of the millennial generation in the teaching and learning process without limits of place and time. Teaching and learning in online school is implementing the educational technology that is based on specific objectives, according to the study of human learning and dissemination, and the use of human and Non-human resources, to promote a more effective teaching of a systematic design, implementation, The method of evaluating the whole process of learning and teaching doing in online. Online school is an online-based school where the millennial generation can attend class without having to come in real class because education as a fact exists objectively, and the students receive formal teaching on the subject [11]. Learning from GIS in education for sustainable development in Singapore online school is a part of teaching and learning without limit in the distance and having a significant impact on improving the ability of students. Because the teacher in online does learning. Teaching and 
learning are doing with trying to find the rhythm in education for sustainable into exciting When doing distill, stylize, and give the millennial generation do interpretation that their lesson not enough to get information from the teacher but also something they can be part of constructing their knowledge between their experience and their mind. Also education more emphasis on introspection, selftransformation of the educational concept. Like in Singapore to satisfy those needs, Ministry of Education Singapore officials acknowledge that the education system must change from a traditional teacher-directed to a student-centered approach. The involves moving toward self-directed, engaged, and creative ways of learning [12]. The online school is a way to reform the education system from a traditional teacher-directed to a student-centered approach. Students will do teaching and learning. When teachers have actively participated in defining objectives and in selecting or constructing evaluation instruments, they return to the learning problems with great vigorous and remarkable creativity [13]. It means the teacher giving the millennial generation to explore their mind and creativity by their self. To do that the parents have to know and understand the concept of curriculum in the school, including the four parts of educational activities includes educators, educational goals, educational contents, and educational forms [14]. Teaching and learning in online school present student-centered in real life, and the teacher only make the lesson plan and make clear instructions about the material that the millennial generation will do.

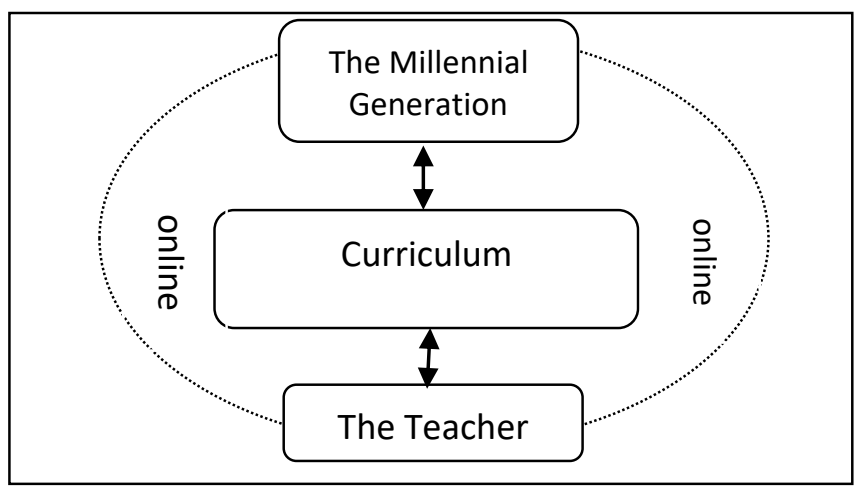

Figure 2. Teaching and Learning in Online School

Teaching and learning in online school show about using technology in learning. This approaches evolved from early uses of teaching tools and have rapidly expanded in recent years to include such devices and approaches as mobile technologies, virtual and augmented realities, simulations and immersive environments, collaborative learning, social networking, cloud computing, flipped classrooms, and more [15]. No matter which perspective on learning is favored, learning in the context of society today, whether at school, university, work or in informal situations, is occurring through increasingly rapid interaction amongst people, technologies, places, and spaces. The increasing pace of learning and change internationally is one of the conventional forces of globalization of education that is shaping societies and education systems on all continents. Today, we have a more complete and immediate sense of the experiences of others through a convergence of the space and resequencing of the time in which learning takes place [16]. [17]established that teaching and learning of the Bureaucratic, Hierarchic, Individualist, and Egalitarian social worlds differ in their rules for handling information with a variance in the way information is constructed and related. Educators have the opportunity to understand in more significant depth differences that characterize social and cultural experience by recognizing the four social worlds of Cultural Theory. The following sections delineate each of the four social worlds concerning the perception of acquiring knowledge and information, learning purpose and value, and the roles of the educator and learner. Teaching and learning in online school will never see of the Bureaucratic, Hierarchic, Individualist, and Egalitarian. All the rules in teaching and learning are about how to improve the ability of students with online instruction. Otherwise, the learner develops their culture by doing their task and fulfil their duties in learning. The teacher in online-teaching-online has the authority to make his rule in instruction.

\subsection{The advantages and disadvantages of an online school}

Nowadays, there is no standard definition of education in academic circles. In many studies, teaching practical ability is often the same as teaching ability and teaching skills. "If we take classroom teaching as logic and construct it from the theory of teaching theory, it mainly includes teaching design 
ability, teaching implementation ability, teaching evaluation ability, and teaching improvement ability. It usually refers to the psychological characteristics of teachers' personality when they are engaged in educational and teaching activities and accomplishes educational and teaching tasks in which will influent the advantages and disadvantages of online school. The advantages of an online school, such as: (a) The millennial generation can attend the school wherever and whenever they want; (b) The millennial generation could be close by their relatives because have more time with family; (c) When the disaster happened, the school easy to start again because of No wasting time, No wasting money to build a building of the school; (d) The millennial generation has much time to do many things without wasting their time on the way; (e) The millennial generation update and knowing what happened in the world; (f) Open their phone for studying and doing something new; (g) Learning in online and have classmate not only from one place. But also in another area; (h) Competition with fair because to get and to make some product or innovation need the capability to read some articles; (i) Update with new research; (j) Buy their task slow but sure they become a programmer; (k) Keep the environment from destroying the forest to build a school.

The disadvantages of an online school, such as: (a) it will be difficult in the urban area because it needs strong internet to connect the online school program; (b) The millennial generation less socialization in using their physic; (c) When the disaster happened they are feeling traumatic and difficult to start; (d) some of the millennial generations spare their time in-game player; (e) The millennial generation does not know to open some app to know the condition of the other countries in the world; (f) sometimes, they open their phone for play the game; (g) The millennial generation has not much money to buy pulse for connecting internet; (h) the millennial generation is always busy with their self and lazy to socialization; (i) the millennial generation is lazy to read and only enjoy playing the game player (j) Being no productive and no innovation; (k) Only seeing a new program without innovation; (1) No office building to meet between the teachers and the students.

\subsection{Online school doing some tasks in nature system}

Online school is an investment for economic growth while doing the task in nature system. The difficult situation has puzzled educational theory research and practice development. On nature system, the teaching and learning will be done without destroying the environment, without destroying a land. The online school is balancing the damage of the environment. Doing activities in online school by nature system keep up of the climate. As we know, in millennial generation phenomena of climate change become a guess because nothing specific reason to explain that.

Recently, some scientists not only getting a new species in this world but also discover a new disease and very danger to an environment. These caused by a disaster, the functioning of a society, causing widespread human, material, or environmental losses which exceed the ability of the affected society to cope using its resources" [18]. Many people must know that online school implementing nature system, and it is an institution designed to provide learning spaces and learning environments for the millennial generation.

Online school is like learning without school or un-schooling and learning in un-schooling almost the same with learning on nature. The millennial generation is studying the lesson without a school building. The millennial generation will growth without missing their potential within their skills, missing knowledge, and missing information. The millennial generation guided their self and used to in and how to fit learning into daily routines. Generally, almost in their activities, they do by their self. The students must keep their programs and operating system up to date. Software developers continually discover new security problems, and they regularly issue updates, patches, and fixes. Students should routinely check for updates for their computer's operating system and software [19]. Thus, by the online school, the millennial generation will do their homework and some tasks naturally and supporting video and picture and then upload what they did in their account. Therefore, the implementation of online school can be seen in the millennial generation task. In this education system, the millennial generation will make their task with improvisation and innovation. The task will do in nature and continue to upload the task in their account. Thus, the other will see what they have been done. By this education system, it will show that if education is to succeed in its enormous task, it must be organized around the four fundamental types of learning which throughout a person's life, will in a way be the pillars of knowledge: Learning to Know - that is acquiring the instruments of understanding, Learning to Do - so as to act creatively in one's environment, Learning to Live Together - so as to participate and cooperate with other people in all human activities; Learning to Be - an essential progression which proceeds from the previous three culminating in the development of 
every child's personality so that he/she is able to act with greater autonomy, judgment, and personal responsibility [20]. The four pillars of education will be implemented in an online class without destroying the environment. The student in that school learning and doing activities in the environment, not in a class because their class is their environment or around their lives.

Also, once experience online school is like un-schooling, society will realize that there is much more to it than just dropping the curriculum. It becomes a learning lifestyle - one where parents and children together enjoy exploring their interests and passions, learning along the way; one that evolves to inform our outlook on just about any situation that arises. Some like to call it a life learning because what we are doing is learning through living. So, an online school becomes an excellent choice for the millennial generation as a disaster solution. Because education in Indonesia must not separate from the industrial revolution, the millennial generation will have a healthy life and far from pollution. Online school is also supported nature school is also teaching the millennial generation by online to plant the trees and giving life to the next generation with the health environment and healthy air. Therefore on nature school for rich and poor alike. Instead, the millennial generation will study the essence of knowledge for sustainable development.

\section{Conclusion}

Education for sustainable development must change the different strategy to cultivate the transformation of education. Three aspects should pay attention such; the location of the country, the habitual, and lifestyle of the young generation. Because to change the mind of the millennial generation is not want help much by others. The millennial generation during this time without commando change their habit and their lifestyle that they can improve their ability by their self. It is no limit, and the limit exists only in mind. The online school is one of the solutions coherent with the location, habitual of the millennial generation, and their lifestyle. Also, an online school is easy to do, a real condition, and sustainable for education. The online school will help the millennial generation to expand their habit, their relation, and their link to communicate up in their real condition in the local area, national, and international without destroying the environment.

\section{Acknowledgment}

This Research is a collaboration between Ahmad Dahlan University and Harbin Normal University. I express my gratitude to all those who have helped in completing this paper. Hopefully, this paper is useful and used as material for further research.

\section{References}

[1] Wikipedia, "Sustainable Development," 2018. .

[2] BNPB, "Badan Nasional Penanggulangan Bencana: Data Informasi Bencana Indonesia," 2018. .

[3] Sky News, "Ring of fire: Why Indonesia has so many earthquakes," Sky News. .

[4] Matthew B. Miles, A. Michael Huberman, and J. Saldaña, "Qualitative Data Analysis: A Methods Sourcebook," Third Edit., United States of America: Sage Publications, 2014.

[5] R. Pring, "Philosophy of Education: Aims, Theory, Common Sense and Research," New York. Continuum, 2004.

[6] C. P. Lim and M. S. Khine, Globalisation, Comparative Education and Policy Research: Comparative Information Technology (Languages, Societies and the Internet). Australia: Springer, 2009.

[7] C. L. Daugherty and C. Walker, "From Evolution to Revolution: Updates to Effective ELearning Model Help Facilitate Better Learning," J. Res. Innov. Teach., vol. 3, no. 1, pp. 5260, 2010.

[8] D. Tao, L. He, and Y. He, Research Series on the Chinese Dream and China's Development Path: Cultural Studies in Modern China. Jinan, Shandong: Springer, 2017. 
[9] Z. Nuryana and Suyadi, "Development Based on Hidden Curriculum at the Disaster-Prone School," J. Educ. Learn., vol. 13, no. 2, pp. 219-225, 2019.

[10] N. Calder and K. Larkin, Mathematics Education in the Digital Era Using Mobile Technologies in the Teaching and Learning of Mathematics, Volume 12. Cham, Switzerland: Springer, 2018.

[11] Mette Arleth, GIS for Sustainable Development. London: CRC Press, 2006.

[12] B. Wong and S. Hairon, School Leadership and Educational Change in Singapore. Singapore: Springer, 2019.

[13] L. J. Cronbach, "Evaluation in Education and Human Services," First Edit., G. F. Madaus, C. Hill, and Daniel L. Stufflebeam, Eds. New York: Kluwer Academic Publishers, 2002.

[14] 陈小民, “教育学原理对教育技术学的启示,” China Acad. J. Electron. Publ. House, 2011.

[15] J. M. Spector and J. Yang, Educational Technology: A Primer for the 21 st Century. Singapore: Springer, 2019.

[16] R. A. Ellis, Spaces of Teaching and Learning Integrating Perspectives on Research. Australia: Springer, 2018.

[17] S. Ashdown, "The Influence of Social Worlds on Engaging Ideas Shelley Ashdown," J. Res. Innov. Teach., vol. 3, no. 1, pp. 7-23, 2010.

[18] L. Bosher and Ksenia Chmutina, Disaster Risk Reduction for the Built Environment. Chennai, India: Wiley Blackwell, 2017.

[19] D. Fodeman and M. Monroe, Safe Practices for Life Online, SECOND EDI. Washington DC: the International Society for Technology in Education, 2012.

[20] P. Shrimal and M. P. Sharma, "UNESCO 's Four Pillars of Education, Implications for Schools," Educ. India J. A Q. Ref. J. Dialogues Educ., vol. 1, no. August 2012, pp. 1-10, 2012. 